\title{
Similarities and Differences in the Underlying Factors Influencing Male and Female Students of Technical Universities in the Choice of Banks: Evidence from Takoradi Technical University, Ghana
}

\author{
Emmanuel Mensah Baah ${ }^{1}$, Emefa Akua Amponsah ${ }^{2}$, Robertson Asare Otoo ${ }^{1}$ \\ ${ }^{1}$ Department of Mathematics, Statistics and Actuarial Science, Faculty of Applied Sciences, Takoradi Technical University, \\ Takoradi, Ghana \\ ${ }^{2}$ Department of Textile Design and Technology, Faculty of Applied Arts and Technology, Takoradi Technical University, \\ Takoradi, Ghana \\ Email: *emmanuel.baah@ttu.edu.gh
}

How to cite this paper: Baah, E.M., Amponsah, E.A. and Otoo, R.A. (2021) Similarities and Differences in the Underlying Factors Influencing Male and Female Students of Technical Universities in the Choice of Banks: Evidence from Takoradi Technical University, Ghana. Applied Mathematics, 12, 1216-1235.

https://doi.org/10.4236/am.2021.1212078

Received: November 8, 2021

Accepted: December 25, 2021

Published: December 28, 2021

Copyright $\odot 2021$ by author(s) and Scientific Research Publishing Inc. This work is licensed under the Creative Commons Attribution International License (CC BY 4.0).

http://creativecommons.org/licenses/by/4.0/

\begin{abstract}
Background: This paper is a follow up to an earlier one on a study that sought to determine the factors that, in general, influence Takoradi Technical University students' selection of banks, given the keen competition in the banking sector in Ghana. Having found the said factors in the first study, and in the face of evidence of a difference in the factors that influence bank choice elsewhere with respect to sex, the study whose findings is the subject of this paper sought to establish whether there is any such dichotomy amongst Takoradi Technical University students. Objectives: The study sought to 1) determine the factors that influence the selection of banks by males, 2) determine the factors that influence the selection of banks by females, and 3) determine whether there are any differences and similarities between male and female students with respect to the factors that influence bank selection. Methods: Data was obtained from 545 students, comprising 364 male students and 181 female students through a cross-sectional survey and was analysed using the statistical method of factor analysis, having initially established through the chi-square test of independence that bank choice and sex are not independent. Results: Four (4) factors were identified as influencing bank selection amongst the female students as against six (6) in the case of the male students. The factors identified for the female students are Customer Experience, Third Party Influence, E-banking, and Access to ATMs and that for the male students are Secure E-banking, Customer Experience, Promotion
\end{abstract}


Strategy, Intelligent Responsiveness, Access to ATMs and Third Party Influence. Conclusion: Male and female students of Takoradi Technical University differ with respect to some of factors that influence bank choice. Even for the factors that are common, the importance female students attach to them is not the same as that of male students. The factors male students consider when making bank choices appear to be more strategic and wide-ranging than the females, with the latter tending to place premium on customer experience more than the former.

\section{Keywords}

Bank Choice, Customers, Technical Universities, Students, Differences

\section{Introduction}

There are often, at least, subtle differences in the way males and females approach issues in many spheres of life. According to Mitchell and Walsh [1] and Kraft and Webber [2], gender plays a significant role in determining consumer behavior; males and females tend to have different interests, expectations and needs, and adopt different methods to satisfy these needs and interests. Heermann [3] identified four areas in marketing communication alone, where men and women differ, they include: trust, use of language, lifestyle and decision making. While this paper is not concerned with marketing per se, the forgoing, nonetheless, should interest entities that would want to sell products and services to the public, and affirm that men and women differ with respect to some areas of life. Kraft and Webber [2] reports of a study at the University of Wisconsin which found that women are far more likely to retain what exist and occurs around them than men, and are as a consequence more receptive to branding messages that are tailored to their circumstances and natural inclinations than men [2]. It therefore makes sense to seek to appreciate what would work for males and females. As a result of the differences between males and females with respect to interests, expectations and needs, there is the need for organisations to identify and define the respective markets presented by males and females so the right products can be tailored for them [2].

In particular, differences in the way males and females approach bank selection have been found in several places. Mokhlis [4] identified sex as a factor that influences bank selection in Malaysia. A study by Srivatsa and Srinivasan [5] involving customers in the Indian banking sector showed gender differences among respondents. Their study found that males and females behaved differently in respect of the factors that influence their choice of banks and found that females prioritized convenience more than their male counterparts. Similarly studies in Bosnia-Herzegovina by Cicic, Brkic, and Agic [6] also found significant differences among the factors that influence the choice of banks by male and female students. Their study identified factors such as recommendations by family and 
friends and conducive, relaxed and friendly environment as factors females consider in bank selection, whiles males considered low-interest rate on loans, higher return on investment, reputation of bank and provision of credit cards as the factors that influence their preference in one bank over the other. Also, Mokhlis et al. [7] found statistically significant differences between males and females in bank selection criteria. Females consider factors such as the attractiveness of the bank, proximity, availability of Automated Teller Machines (ATMs), availability of the bank's branches across different locations that enables easy access to their services, return on investments, and safety feelings. Male respondents tended to be influenced by financial benefits and marketing promotion of banks in choosing banks as compared to their female counterparts [4].

In Ghana, a number of factors (latent variables) have been put forward as influencing bank choice amongst potential customers of banks. They include "ease of transaction", "professionalism of banking personnel", "system efficiencies", "proximity" and "originality of bank" [8]. A study of Takoradi Technical University (Ghana) students, which was published with the title "Determinants of technical university students choice of banks: empirical evidence from Takoradi Technical University" [9], a precursor of this article, found "robust e-banking", "customer experience", "accessibility of ATMs" and "third party influence" [9]. These factors (latent variables) express themselves in the form of indicator variables that are measurable as opposed to the latent variables which are somewhat not directly measurable or observable. What appears not to have been explored locally, is whether there is evidence of a difference between males and females with respect to the factors that influence bank choice. In the face of evidence of existence of differences between males and females relative to factors that influence bank choice elsewhere, the study reported in this paper was carried out to fill the gap identified above with the following objectives: 1) determine the factors that influence the selection of banks by male students, 2) determine the factors that influence the selection of banks by female students, and 3) determine whether there are any differences and similarities between male and female students with respect to the factors that influence bank selection.

As indicated by Mokhlis [4], after reviewing several studies on banking preferences, gender differences in retail banking are often considered as a side issue. This study on gender preferences among technical university students is an attempt to understand the gender differences regarding banking preference among technical university students in Ghana. It will enable banks in Ghana to understand the criteria used by young prospective customers in choosing banks, thereby enabling them to develop products, services and institute measures to satisfy the needs of both male and female (prospective) customers; and thus attract both male and female customers to their banks. Should the study results indicate that there exists segmentation in bank preferences with respect to males and females, it will help banks to prioritize their products and develop specific products along the lines of the segmentation. 
As pointed out above, this study is a follow up to an earlier one that looked at what, in general, influences bank selection amongst Technical University students, using Takoradi Technical University (TTU) as a case study.

\section{Review of Methods}

The data for the study reported in this paper was collected through a cross-sectional survey of students of Takoradi Technical University, Ghana. The data was analysed using the statistical methods of chi-square test of independence and factor analysis in the statistical programming environment of $\mathrm{R}$ [10]. A review of the major issues involved in the data collection and analysis are given below.

\subsection{Collection of Data}

The collection of the data took place over the months of July to November 2020. The government of Ghana suspended on-campus studies in the country's educational institutions on March 15, 2020 due to need for physical distancing, to forestall the possibility of spread of the COVID-19 pandemic. Following the suspension, students were sent home while academic work continued online. Students were asked to come back to campus for the end-of-second-semester examinations in batches, with the final-year students, the second-year students and other groups, and first-year students reporting to the campus in that order over the period specified above. The full complement of the student body was therefore not on campus at any point in time during this period. As many students as possible were interviewed when the various batches were on campus to take the end-of-semester exams. Twenty-five questions, each of which measures the responses on a 5-point differential scale ranging from 1-“strongly disagree" to 5- "strongly agree", was administered to the respondents. Out of the 641 students interviewed, 545 of them provided answers to all the questions. The remaining 96 of the respondents did not provide answers for all the questions. The analysis was carried out on the 545 complete questionnaires only. Of the 545 respondents, 364 were male and 181 were female. The sample sizes of 364 and 181 are individually adequate for factor analysis. In particular, Hair et al. [11] report that for factor analysis, the sample size should be at least five times the number of variables under consideration in a study.

The original intention was to collect data from all ten Technical Universities in Ghana, so that the results of the study could be generalized. However, the study was limited to Takoradi Technical University to avoid the difficulties associated with the COVID-19 disease.

\subsection{Statistical Methods}

A review of the statistical methods of chi-square and factor analysis is presented below:

\subsubsection{Chi-Square Test of Independence}

If a random sample of data has $A_{i}, i=1,2, \cdots, r$ levels of one classification and 
$B_{j}, j=1,2, \cdots, c$ levels of another classification, then the Chi-square test of independence can be used to ascertain whether or not Classification $A$ and Classification $B$ are independent. Given that $n_{i j}$ is the number of items possessing both attributes $A_{i}$ and $B_{j}$, then the total number of items with attribute $A_{i}, i=1,2, \cdots, r$ is given by $\sum_{j=1}^{c} n_{i j}=n_{i}$. and the total number of items with attribute $B_{j}, j=1,2, \cdots, c$ is given by $\sum_{i=1}^{r} n_{i j}=n_{. j}$ and the overall number of observations is given by $\sum_{i=1}^{r} \sum_{j=1}^{c} n_{i j}=n_{. .}$. The entities $n_{i .}$ and $n_{. j}$ are free to vary as they are subject to chance while $n_{.}$is fixed. If the chance apportioning of the data over the various levels of $A$ has no relationship with that over the various levels of $B$, then $A$ and $B$ are said to be independent. In which case the product rule of probability dictate that:

$$
P\left(A_{i} \cap B_{j}\right)=P\left(A_{i}\right) \times P\left(B_{j}\right)
$$

Suppose $P\left(A_{i} \cap B_{j}\right)=P_{i j}$, then

$$
P\left(A_{i}\right)=\sum_{j=1}^{c} P_{i j}=P_{i}
$$

and

$$
P\left(B_{j}\right)=\sum_{i=1}^{r} P_{i j}=P_{. j}
$$

It follows that if $A$ and $B$ are independent, then

$$
P_{i j}=P_{i .} \times P_{. j}
$$

Now

$$
\begin{gathered}
\hat{P}_{i .}=\frac{n_{i .}}{n_{. .}} \\
\hat{P}_{. j}=\frac{n_{. j}}{n_{. .}}
\end{gathered}
$$

and

$$
\hat{P}_{i j}=\hat{P}_{i .} \times \hat{P}_{. j}
$$

Given that $e_{i j}$ is the expected number of items with both attributes $A_{i}$ and $B_{j}$ when $A$ and $B$ are independent, then

$$
e_{i j}=n_{. .} \cdot P_{i j}
$$

So

$$
\hat{e}_{i j}=n_{. .} \cdot \hat{P}_{i j}=n_{. .} \cdot \hat{P}_{i .} \times \hat{P}_{. j}=n_{. .} \cdot \frac{n_{i .}}{n_{. .}} \cdot \frac{n_{. j}}{n_{. .}}=\frac{n_{i .} \times n_{. j}}{n_{. .}}
$$

The Pearson's statistic given by

$$
\chi^{2}=\sum_{i=1}^{r} \sum_{j}^{c} \frac{\left(n_{i j}-e_{i j}\right)^{2}}{e_{i j}}
$$

which is approximately Chi-square distributed with $(r-1)(c-1)$ degrees of freedom, provides a measure of how close the empirical data come to the expected distribution of the data when $A$ and $B$ are independent, and one would 
reject the belief of $A$ and $B$ being independent when the chance of having a data as unusual as the current data is lower than some permissible threshold.

The $e_{i j} s$ are estimated by $\hat{e}_{i j}$ s as outlined above [12].

The statistic given by

$$
V=\sqrt{\frac{\chi^{2}}{n_{. .} \times m}}, \quad m=\min (r-1, c-1)
$$

and known as the Cramer's $\mathrm{V}$, is a measure of the strength of the association between $A$ and $B$ and varies between 0 and 1, taking the value 0 when $A$ and $B$ are independent and 1 when $A$ and $B$ are perfectly associated [13].

\subsubsection{Factor Analysis}

Often the nature of the variables of interest in an investigation is unknown or they are not directly measurable. However, these latent variables, otherwise known as factors may be correlated with other indicator variables that are measurable. The factors could be uncovered or measured by capitalizing on the correlation between the factors and the indicator variables once data on the indicator variables are available, through the statistical technique of factor analysis [11] [14] [15] [16].

Suppose $X^{\prime}=\left(X_{1}, X_{2}, \cdots, X_{P}\right)$ is the vector of observable (indicator) variables that are correlated with the vector of latent variables (factors) $F^{\prime}=\left(F_{1}, F_{2}, \cdots, F_{m}\right)$ where $m \ll p$, with mean of $X$ given by $\mu=E[X]=\left(\mu_{1}, \mu_{2}, \cdots, \mu_{p}\right)^{\prime}$. Suppose also that the vector of possible error terms associated with each $X_{i}, i=1,2, \cdots, p$, is $\varepsilon^{\prime}=\left(\varepsilon_{1}, \varepsilon_{2}, \cdots, \varepsilon_{p}\right)$ respectively. Then we are looking at a model in which the response variable is the mean corrected vector $(X-\mu)_{p \times 1}$, given by

$$
(X-\mu)_{p \times 1}=L_{p \times m} F_{m \times 1}+\varepsilon_{p \times 1}
$$

where $L_{p \times m}$ is a $p \times m$ matrix composed of the coefficients $l_{i j}, i=1,2, \cdots, p ; j=1,2, \cdots, m$, which are referred to as factor loadings [14].

A factor model that satisfies the following conditions are desired:

1) the factors are uncorrelated;

2) the specific error terms are uncorrelated;

3) the specific error terms and the factors are uncorrelated.

This implies that

$$
\begin{gathered}
E[F]=O_{(m \times 1)}, \quad E[\varepsilon]=O_{(p \times 1)}, \quad \operatorname{Cov}(F)=I_{(m \times m)} \\
\operatorname{Cov}\left(\varepsilon_{i}, \varepsilon_{j}\right)=O, \operatorname{Cov}\left(F_{i}, \varepsilon_{j}\right)=O
\end{gathered}
$$

where $O$ is a matrix of zeros.

Such a factor model is referred to as the orthogonal factor model, and is such that the $l_{i j}$ 's (also known as pattern loadings) are the simple correlations (structural loadings) between the indicator variables $X_{i}, i=1,2, \cdots, p$ and the factors $F_{j}, j=1,2, \cdots, m$.

The correlation amongst the indicator variables $X_{i}, i=1,2, \cdots, p$ is as a result of the influence of the shared latent dimensions (factors). Indicator variables 
that are influenced by the same latent factors tend to correlate highly amongst themselves and with those factors. Factor analysis capitalises on this situation to identify the latent factors.

The variance variable $X_{i}$ shares with factor $F_{j}$ is $l_{i j}^{2}$. So the total variance (communality) $X_{i}$ shares with all $m$ factors is given by [14] [15] [16]:

$$
l_{i 1}^{2}+l_{i 2}^{2}+\cdots+l_{i m}^{2}
$$

\subsubsection{Principal Component Factoring}

Principal Component Factoring (PCF) refers to factor analysis using principal component analysis-one of several but popular approaches by which factor analysis could be done. Principal Component Analysis facilitates the formation of a new set of uncorrelated variables (called principal components (PCs)), which are as many as the original (observable) variables from which they are formed. The first PC accounts for the highest of the variance in the data, the second PC accounts for the highest of the variance in the data unaccounted for by first PC, the third PC accounts for the highest of the variance in the data unaccounted for by the first two PCs, and so on. Data reduction could be achieved by replacing the original set of observable variables with the first few PCs if they, together, happen to account for a significant portion of the variance in the data, as much of the information in the data would have been explained thereby. PCF uses this approach to explain the correlations among the indicator variables and in this manner identify the underlying dimensions answerable for the correlations amongst the indicator variables [14] [15] [16].

The PCs $Y_{1}, Y_{2}, \cdots, Y_{p}$, which are thought to be linear combinations of the indictor variables $X_{i}, \quad i=1,2, \cdots, p$, are given by

$$
\begin{gathered}
Y_{1}=\beta_{11} X_{1}+\beta_{12} X_{2}+\cdots+\beta_{1 p} X_{p} \\
Y_{2}=\beta_{21} X_{1}+\beta_{22} X_{2}+\cdots+\beta_{2 p} X_{p} \\
\vdots \\
Y_{p}=\beta_{p 1} X_{1}+\beta_{p 2} X_{2}+\cdots+\beta_{p p} X_{p}
\end{gathered}
$$

where $\beta_{i j}, i=1, \cdots, p ; j=1, \cdots, p$, are coefficients (weights). The above set of linear combinations could be written as

$$
Y=\beta X
$$

where

$$
Y^{\prime}=\left(Y_{1}, Y_{2}, \cdots, Y_{p}\right), \quad \beta=\left(\begin{array}{cccc}
\beta_{11} & \beta_{12} & \cdots & \beta_{1 p} \\
\beta_{21} & \beta_{22} & \cdots & \beta_{2 p} \\
\vdots & \vdots & \ddots & \vdots \\
\beta_{p 1} & \beta_{p 2} & \cdots & \beta_{p p}
\end{array}\right), X^{\prime}=\left(X_{1}, X_{2}, \cdots, X_{P}\right)
$$

Depending on the choice of the coefficients, the cumulative variance of the PCs $Y_{1}, Y_{2}, \cdots, Y_{p}$, could exceed the variance of the observed data, which is not realistic. The situation is remedied by imposing the following conditions [14] [15] [16]:

$$
\beta_{i}^{\prime} \cdot \beta_{j}=0 \text { for all } i \neq j
$$


and

$$
\beta_{i}^{\prime} \cdot \beta_{i}=1
$$

where

$$
\beta_{i}^{\prime}=\left(\beta_{i 1}, \beta_{i 2}, \cdots, \beta_{i p}\right)
$$

If the standardized variables $Z^{\prime}=\left(Z_{1}, Z_{2}, \cdots, Z_{P}\right)$ are used, where

$$
Z_{i}=\left(\sigma_{i i}\right)^{-1}\left(X_{i}-\mu_{i}\right), E\left[X_{i}\right]=\mu_{i} \text { and } \operatorname{Var}\left(X_{i}\right)=\sigma_{i i}^{2}
$$

We have

$$
\begin{gathered}
E\left[Z_{i}\right]=0, \quad \operatorname{Var}\left(Z_{i}\right)=1, \quad i=1, \cdots, p, E[Z]=0 \text { and } \\
\rho=\operatorname{Cov}(Z)=\left(U^{1 / 2}\right)^{-1} \Sigma\left(U^{1 / 2}\right)^{-1}
\end{gathered}
$$

where $\rho$ and $\Sigma$ are the correlation matrix and variance-covariance matrix of $X$ respectively and $U^{1 / 2}$ is a diagonal standard deviation matrix as specified below:

$$
\rho=\left[\begin{array}{cccc}
\frac{\sigma_{11}^{2}}{\sigma_{11} \sigma_{11}} & \frac{\sigma_{12}^{2}}{\sigma_{11} \sigma_{22}} & \cdots & \frac{\sigma_{1 p}^{2}}{\sigma_{11} \sigma_{p p}} \\
\frac{\sigma_{12}^{2}}{\sigma_{11} \sigma_{22}} & \frac{\sigma_{22}^{2}}{\sigma_{22} \sigma_{22}} & \cdots & \frac{\sigma_{2 p}^{2}}{\sigma_{22} \sigma_{p p}} \\
\vdots & \vdots & \ddots & \vdots \\
\frac{\sigma_{1 p}^{2}}{\sigma_{11} \sigma_{p p}} & \frac{\sigma_{2 p}^{2}}{\sigma_{22} \sigma_{p p}} & \cdots & \frac{\sigma_{p p}^{2}}{\sigma_{p p} \sigma_{p p}}
\end{array}\right]
$$

and

$$
\begin{gathered}
\Sigma=\left[\begin{array}{cccc}
\sigma_{11}^{2} & \sigma_{12}^{2} & \cdots & \sigma_{1 p}^{2} \\
\sigma_{21}^{2} & \sigma_{22} & \cdots & \sigma_{2 p}^{2} \\
\vdots & \vdots & \ddots & \vdots \\
\sigma_{p 1}^{2} & \sigma_{p 2}^{2} & \cdots & \sigma_{p p}^{2}
\end{array}\right] \\
U^{1 / 2}=\left[\begin{array}{cccc}
\sigma_{11} & 0 & \cdots & 0 \\
0 & \sigma_{22} & \cdots & 0 \\
\vdots & \vdots & \ddots & \vdots \\
0 & 0 & \cdots & \sigma_{p p}
\end{array}\right]
\end{gathered}
$$

Then the vector $Y^{\prime}=\left(Y_{1}, Y_{2}, \cdots, Y_{p}\right)$ of principal the components could be found by

$$
Y=A^{\prime} Z
$$

where

$$
\begin{gathered}
A=\left[e_{1}, e_{2}, \cdots, e_{p}\right] \\
Z=\left(U^{1 / 2}\right)^{-1}(X-\mu)
\end{gathered}
$$

and

$$
\mu^{\prime}=\left(\mu_{1}, \mu_{2}, \cdots, \mu_{p}\right)
$$


with $\left(\lambda_{i}, e_{i}\right), i=1,2, \cdots, p$ being the eigenvalue-eigenvector pairs of $\rho$ such that

$$
\begin{gathered}
\lambda_{1} \geq \lambda_{2} \geq \cdots \geq \lambda_{p} \geq 0, e_{i}^{\prime} \cdot e_{j}=0 \text { and } e_{i}^{\prime} \cdot e_{i}=1 . \\
\operatorname{Var}\left(Y_{i}\right)=e_{i}^{\prime} \rho e_{i}=\lambda_{i}
\end{gathered}
$$

and

$$
\sum_{i=1}^{p} \operatorname{Var}\left(Y_{i}\right)=\sum_{i=1}^{p} \operatorname{Var}\left(Z_{i}\right)=p
$$

as in PCF, the initial communality of each indicator variable is one. Thus $\lambda_{i} / p$ is the fraction of the variance in the data that can be ascribed to $Y_{i}$.

The degree of correlation between $Z_{j}$ and $Y_{i}$, otherwise referred to as the loading of $Z_{j}$ on $Y_{i}$, given the effect of other variables $Z_{k}, j \neq k$ is given by [14] [15] [16]:

$$
\operatorname{Corr}\left(Y_{i}, Z_{j}\right)=e_{i j} \cdot \lambda_{j}^{(1 / 2)}
$$

\section{Results and Discussions}

The analysis of the data was done for the all-male and the all-female samples separately and the results compared. The rational for this approach, the results of the analysis and the discussion of the findings are as follows:

\subsection{Test of Independence of Sex and Bank Choice}

The question that arises, in the face of the evidence provided in the literature, is whether sex is associated with bank choice, in the case of TTU students. To address this question, the chi-square test of independence was carried out on the composite data from the 545 respondents, as indicated above. As Table 1 shows, the results of the test indicate that there is an association between sex and bank selection as the $p$-value corresponding to the test is $0.006(<0.05$, the conventional threshold for which the test of the hypothesis of an association between two variables $A$ and $B$ could be said to be not significant, if the $p$-value is greater), albeit a weak one given the low value (0.190) of the Cramer's V coefficient.

The above result is consistent with what was found by Amewu and Mensah [8], Owusu-Frimpong [17], Azumah, Rahman and Adzawla [18], who established that there is a link between choice of bank and sex. Srivatsa and Srinivasan [5] also found that there is a difference between men and women with respect to banking preferences. Additionally, Mokhlis [4] found a link between sex and bank choice in Malaysia. Thus there is ample evidence pointing to an association between bank choice and sex, as the above test of independence suggest in the case of Takoradi Technical University Students.

Table 1. Results of test of association between sex and bank choice.

\begin{tabular}{cccc}
\hline Chi-square value & Degrees of freedom & $p$-value & Cramer's V \\
\hline 19.777 & 7 & 0.006 & 0.190 \\
\hline
\end{tabular}




\subsection{Factor Analysis Using the All-Male Sample and the All-Female Sample Separately}

Following the results from the test of independence of sex and bank choice, the data was split into two (as indicated above): an all-male sample and an all-female sample. The idea was to carry out separate analysis for the two samples and compare the results.

\subsubsection{Suitability of Data for Factor Analysis}

Table 2 shows the respective KMO values of 0.89 and 0.83 for the male and female samples (the least for the individual items of the questionnaire for the male and females samples are 0.70 and 0.67 respectively) and the $p$-values for the Bartlett's test of sphericity are both $0.000(<0.05)$. It follows that both samples are not only adequate for, but lend themselves to statistical method of factor analysis as the $p$-values for the Bartlett's test indicate there are significant correlations amongst the variables for both samples [11] [16].

The initial and final total communalities the manifest variables share with the common latent factors are as shown in Table 3 and Table 4 for the male and female samples respectively. In PCF, the initial variance an indicator variable shares with all associated underlying factors is one (1). Seventeen (17) and fourteen (14) variables, respectively of the male sample and the female sample, remained in the final factor solutions out of the twenty-five (25) variables that were initially entered into the analysis. Variables that were found to have communality

Table 2. Results for the KMO measure and Bartlett's test of sphericity for male and female samples.

\begin{tabular}{ccc}
\hline & Male & Female \\
\hline Kaiser-Meyer-Olkin measure of sampling adequacy & 0.890 & 0.830 \\
Bartlett's Test of Sphericity: Approximate Chi-Square & 2127.202 & 784.683 \\
Degrees of freedom & 136 & 91 \\
Significance & 0.000 & 0.000 \\
\hline
\end{tabular}

Table 3. Initial and final communalities of variables for the male sample.

\begin{tabular}{lcclcc}
\hline \multicolumn{1}{c}{ Variable } & Initial & Extraction & \multicolumn{1}{c}{ Variable } & Initial & Extraction \\
\hline Availability of ATM on campus & 1.00 & 0.76 & Influence of parents & 1.00 & 0.70 \\
Availability of 24 hours ATM service & 1.00 & 0.71 & The University uses the same bank & 1.00 & 0.68 \\
Provision of fast and efficient service & 1.00 & 0.69 & $\begin{array}{l}\text { Service provision } \\
\text { (Range of products on offer) }\end{array}$ & 1.00 & 0.63 \\
Convenient branch location & 1.00 & 0.74 & Promotion strategy & 1.00 & 0.59 \\
Appropriate range of service offered & 1.00 & 0.56 & Convenience banking & 1.00 & 0.62 \\
Pleasant bank atmosphere & 1.00 & 0.64 & Digital platforms & 1.00 & 0.64 \\
Staff courtesy & 1.00 & 0.65 & Integration of mobile money services & 1.00 & 0.53 \\
Professionalism of bank staff & 1.00 & 0.62 & Security & 1.00 & 0.62 \\
\hline
\end{tabular}


Table 4. Initial and final communalities of variables for the female sample.

\begin{tabular}{lcclcc}
\hline \multicolumn{1}{c}{ Variable } & Initial & Extraction & \multicolumn{1}{c}{ Variable } & Initial & Extraction \\
\hline Availability of ATM on campus & 1.00 & 0.69 & Professionalism of bank staff & 1.00 & 0.63 \\
Availability of 24 hours ATM service & 1.00 & 0.70 & Mobile banking facilities & 1.00 & 0.63 \\
Appropriate range of service offered & 1.00 & 0.59 & The University uses the same bank & 1.00 & 0.63 \\
Pleasant bank atmosphere & 1.00 & 0.60 & Financial benefits & 1.00 & 0.63 \\
Staff courtesy & 1.00 & 0.63 & Service provision & 1.00 & 0.58 \\
Proximity to the University & 1.00 & 0.63 & Convenience banking & 1.00 & 0.53 \\
Reputation of the bank & 1.00 & 0.57 & Integration of mobile money services & 1.00 & 0.71 \\
\hline
\end{tabular}

less than 0.5 or loaded on more than one factor were dropped from the analysis, in assessing the viability of the variables. Hair et al. [11] recommend that only variables with communality greater than 0.5 should be retained in the analysis, as variables with communality less than 0.5 tend to contribute poorly to the factor solution.

The variables in Table 3 and Table 4 are, therefore, only those that have a final communality of 0.50 or more; accounting for $50 \%$ or more of the initial total communality of one (1) in the final factor solution. The final factor solution for the male and female samples, respectively presented in Table 3 and Table 4, are thus deemed adequate.

\subsubsection{Number of Factors Extracted}

There are at least four criteria for facilitating the decision as to how many factors are to be retained to adequately account for the underlying factor structure of a given data. They include the eigen-value-greater-than-one rule, the scree plot, Horn's parallel analysis and the cumulative percentage of variance explained by the retained factors (components) [11] [16]. For the male sample, the first five components (factors) have eigenvalues greater than one (see Column 2 of Table 5), so going by the eigenvalue-greater-than-one rule, five factors are to be retained for interpretation [11] [16]. The scree plot of Figure 1 shows that the plot line begins to straighten out from the seventh factor onwards, suggesting the retention of six factors for interpretation [11] [16]. The results of Horn's parallel analysis on the male data is presented in Table 6 and Figure 2. The scree plot of the empirical data (unadjusted EV in red, adjusted in black) is cut by the scree plot of the mean eigenvalues of simulated data (Random EV in blue) before the plot point of the seventh eigenvalue of the empirical data (Figure 2) and the adjusted eigenvalues of the first six factors are greater than zero (see Column 2 of Table 6), indicating the first six components can be retained for interpretation [16] [19] [20].

The first five factors account for more than sixty percent $(64.49 \%)$ of the variance in the data, so going by the minimum cumulative variance suggested by Hair et al. [11], five factors can be retained. According to Sharma [16], the 
Table 5. Total variance explained.

\begin{tabular}{|c|c|c|c|c|c|c|}
\hline \multirow{3}{*}{ Component } & \multicolumn{3}{|c|}{ Male } & \multicolumn{3}{|c|}{ Female } \\
\hline & \multicolumn{3}{|c|}{ Initial Eigenvalues } & \multicolumn{3}{|c|}{ Initial Eigenvalues } \\
\hline & Total & $\begin{array}{c}\% \\
\text { of Variance }\end{array}$ & $\begin{array}{c}\text { Cumulative } \\
\%\end{array}$ & Total & $\begin{array}{c}\% \\
\text { of Variance }\end{array}$ & $\begin{array}{c}\text { Cumulative } \\
\%\end{array}$ \\
\hline 1 & 5.912 & 34.776 & 34.776 & 4.695 & 33.536 & 33.536 \\
\hline 2 & 1.532 & 9.010 & 43.786 & 1.648 & 11.772 & 45.308 \\
\hline 3 & 1.405 & 8.265 & 52.051 & 1.347 & 9.619 & 54.926 \\
\hline 4 & 1.111 & 6.536 & 58.587 & 1.067 & 7.624 & 62.550 \\
\hline 5 & 1.004 & 5.907 & 64.494 & 0.790 & 5.640 & 68.190 \\
\hline 6 & 0.761 & 4.474 & 68.968 & 0.714 & 5.100 & 73.290 \\
\hline 7 & 0.671 & 3.947 & 72.915 & 0.639 & 4.567 & 77.858 \\
\hline 8 & 0.622 & 3.659 & 76.574 & 0.580 & 4.143 & 82.001 \\
\hline 9 & 0.590 & 3.469 & 80.043 & 0.542 & 3.874 & 85.875 \\
\hline 10 & 0.515 & 3.031 & 83.074 & 0.502 & 3.588 & 89.463 \\
\hline 11 & 0.498 & 2.931 & 86.005 & 0.428 & 3.054 & 92.517 \\
\hline 12 & 0.457 & 2.686 & 88.691 & 0.418 & 2.982 & 95.499 \\
\hline 13 & 0.434 & 2.555 & 91.246 & 0.342 & 2.441 & 97.941 \\
\hline 14 & 0.411 & 2.420 & 93.666 & 0.288 & 2.059 & 100.000 \\
\hline 15 & 0.384 & 2.258 & 95.924 & & & \\
\hline 16 & 0.358 & 2.108 & 98.032 & & & \\
\hline 17 & 0.335 & 1.968 & 100.000 & & & \\
\hline
\end{tabular}

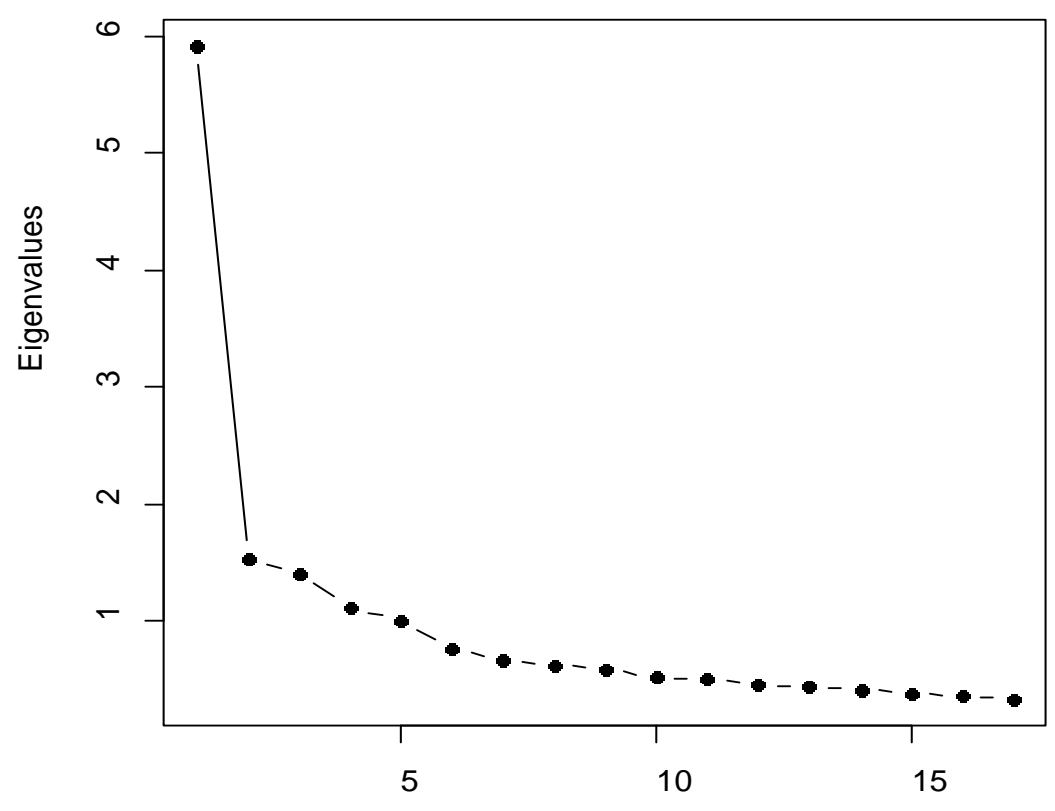

Factors

Figure 1. Plot of eigenvalues against factor number for the male sample. 
Table 6. Results of Horn's parallel analysis for 5000 iterations using the mean estimate for the Male and female samples.

\begin{tabular}{|c|c|c|c|c|c|c|}
\hline \multirow[b]{2}{*}{ Factor } & \multicolumn{3}{|c|}{ Male } & \multicolumn{3}{|c|}{ Female } \\
\hline & $\begin{array}{c}\text { Adjusted } \\
\text { Eigenvalue }\end{array}$ & $\begin{array}{l}\text { Unadjusted } \\
\text { Eigen value }\end{array}$ & $\begin{array}{c}\text { Estimated } \\
\text { Bias }\end{array}$ & $\begin{array}{c}\text { Adjusted } \\
\text { Eigenvalue }\end{array}$ & $\begin{array}{l}\text { Unadjusted } \\
\text { Eigenvalue }\end{array}$ & $\begin{array}{c}\text { Estimated } \\
\text { Bias }\end{array}$ \\
\hline 1 & 4.891 & 5.337 & 0.447 & 3.531 & 4.116 & 0.585 \\
\hline 2 & 0.532 & 0.893 & 0.361 & 0.570 & 1.025 & 0.455 \\
\hline 3 & 0.517 & 0.815 & 0.298 & 0.357 & 0.716 & 0.359 \\
\hline 4 & 0.206 & 0.449 & 0.243 & 0.119 & 0.396 & 0.277 \\
\hline 5 & 0.198 & 0.392 & 0.194 & -0.029 & 0.174 & 0.203 \\
\hline 6 & 0.043 & 0.191 & 0.148 & -0.022 & 0.112 & 0.135 \\
\hline 7 & -0.073 & 0.032 & 0.105 & -0.044 & 0.029 & 0.072 \\
\hline 8 & -0.046 & 0.019 & 0.065 & -0.028 & -0.015 & 0.013 \\
\hline 9 & -0.051 & -0.025 & 0.026 & 0.004 & -0.040 & -0.044 \\
\hline 10 & -0.062 & -0.074 & -0.011 & 0.007 & -0.092 & -0.098 \\
\hline 11 & -0.071 & -0.119 & -0.048 & -0.036 & -0.188 & -0.152 \\
\hline 12 & -0.036 & -0.121 & -0.085 & -0.002 & -0.208 & -0.206 \\
\hline 13 & -0.029 & -0.150 & -0.121 & 0.008 & -0.255 & -0.262 \\
\hline 14 & -0.004 & -0.161 & -0.157 & 0.048 & -0.279 & -0.327 \\
\hline 15 & 0.007 & -0.188 & -0.195 & & & \\
\hline 16 & 0.025 & -0.210 & -0.236 & & & \\
\hline 17 & 0.016 & -0.269 & -0.285 & & & \\
\hline
\end{tabular}

Adjusted eigenvalues $>0$ indicate $\quad$ Adjusted eigenvalues $>0$ indicate dimensions to retain; 6 factors retained. dimensions to retain; 4 factors retained.

\section{Parallel Analysis}

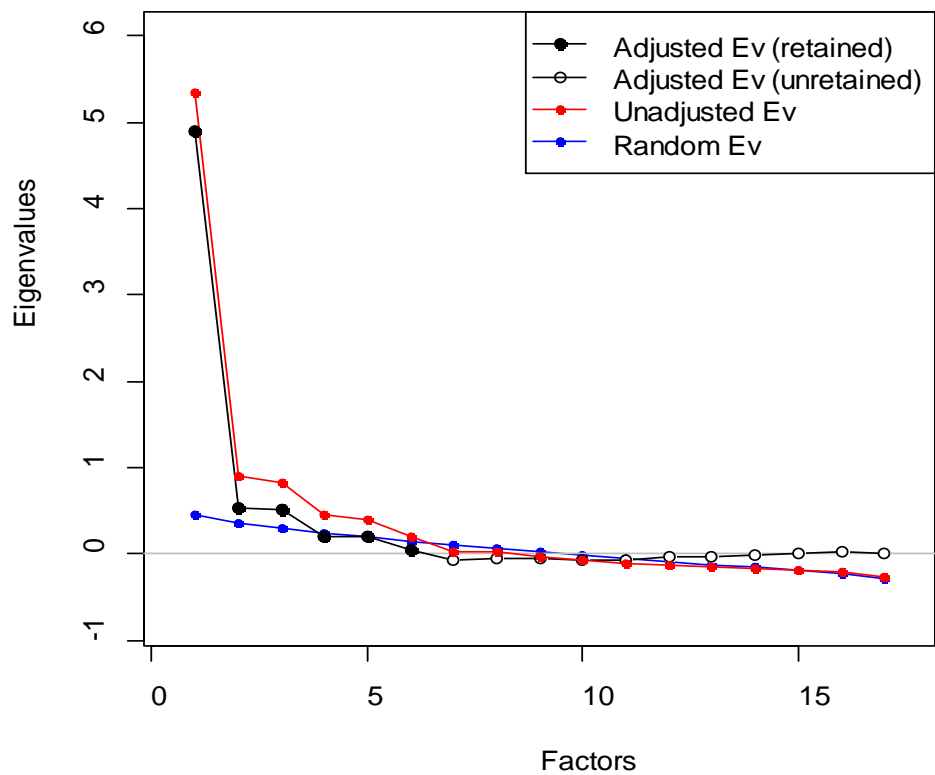

Figure 2. Plot of adjusted, unadjusted and random eigenvalues against factor number, depicting the factors to be retained for further interpretation, for the male sample. 
Horn's criteria has been found to perform creditably well in simulation studies, in deciding how many component to retain. Thus putting the results of the four criteria together and given the performance of the Horn's criteria, one is persuaded to retain the first six factors to account for the structure of what account for bank selection amongst male TTU students. More so, when the cumulative variance $(68.97 \%)$ of the first six factors is higher than that $(64.49 \%)$ of the first five factors, even though the sixth factor's eigenvalue (0.761) is less than one. Additionally, the six factor solution appear to be more plausible than the five factor solution, from the perspective of the manifest variables loading on the factors. Going by the same token as above and using Figure 3, Figure 4, Table 5 and Table 6, four factors were retained for the female sample.

\subsubsection{Final Factor Solution}

A recommended factor solution is one in which the factors are orthogonal, with each indicator variable in the final factor solution loading highly on only one factor. This was achieved for both the male and female data sets through a Varimax rotation of the factor solutions described above [11] [16]. The final factor solution for both sets of data, after the varimax rotation, is as shown in Table 7 and Table 8. The absolute values of the loadings indicate the degree of correlation between the indicator variables and the factors and hence the extent to which the former impacts the latter [14] [15] [16]. Loadings of 0.30 and 0.45 or higher are deemed significant for the male and female sample sizes of 364 and 181 respectively [11]. However, a minimum loading threshold of 0.50 was used to screen the indicator variables in order to ensure that the final factor solution is of practical significance. The indicator variables loading on the various factors in the final factor solution were sorted in descending order of the absolute value

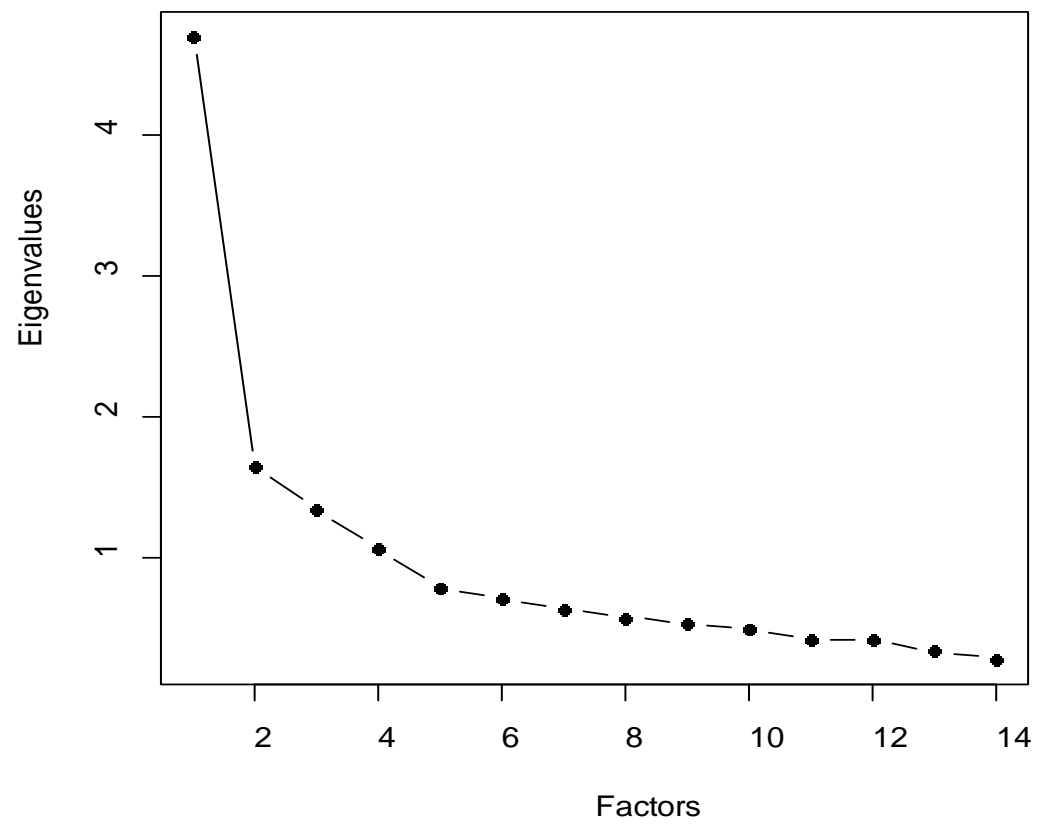

Figure 3. Plot of eigenvalues against factor number for the female sample. 
Parallel Analysis

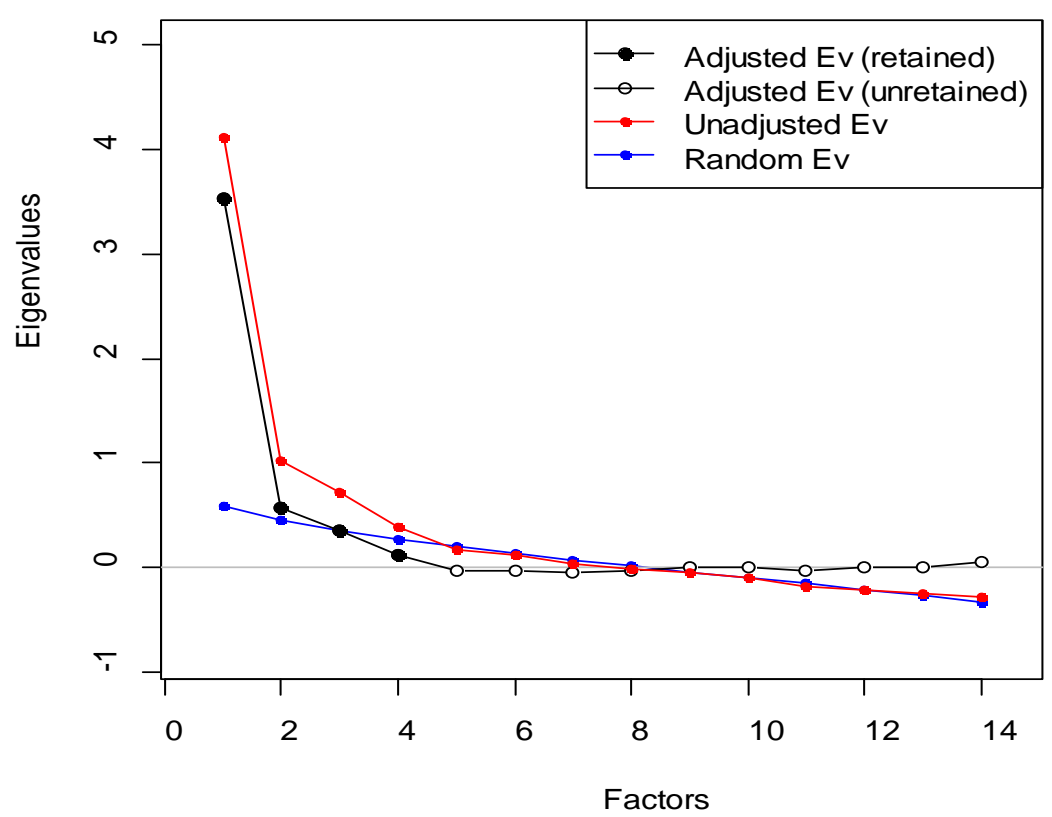

Figure 4. Plot of adjusted, unadjusted and random eigenvalues against factor number, depicting the factors to be retained for further interpretation, for the female sample.

Table 7. Rotated component matrix showing the loadings of the variables on the factors, for the male sample.

\begin{tabular}{|c|c|c|c|c|c|c|}
\hline \multirow{2}{*}{ Variables } & \multicolumn{6}{|c|}{ Components (factors) } \\
\hline & 1 & 2 & 3 & 4 & 5 & 6 \\
\hline $\mathrm{V}_{1}$ Internet banking & 0.78 & & & & & \\
\hline $\mathrm{V}_{2}$ Digital platforms & 0.68 & & & & & \\
\hline $\mathrm{V}_{3}$ Integration of mobile money services & 0.67 & & & & & \\
\hline $\mathrm{V}_{4}$ Security & 0.63 & & & & & \\
\hline $\mathrm{V}_{5}$ Staff courtesy & & 0.74 & & & & \\
\hline $\mathrm{V}_{6}$ Professionalism of bank staff & & 0.74 & & & & \\
\hline $\mathrm{V}_{7}$ Pleasant bank atmosphere & & 0.73 & & & & \\
\hline $\mathrm{V}_{8}$ Promotion strategy & & & 0.73 & & & \\
\hline $\mathrm{V}_{9}$ Service provision (range of products on offer) & & & 0.71 & & & \\
\hline $\mathrm{V}_{10}$ Convenience banking & & & 0.70 & & & \\
\hline $\mathrm{V}_{11}$ Convenient branch location & & & & 0.80 & & \\
\hline $\mathrm{V}_{12}$ Appropriate range of service offered & & & & 0.68 & & \\
\hline$V_{13}$ Provision of fast and efficient service & & & & 0.68 & & \\
\hline $\mathrm{V}_{14}$ Availability of 24 hours ATM service & & & & & 0.84 & \\
\hline $\mathrm{V}_{15}$ Availability of ATM on campus & & & & & 0.81 & \\
\hline $\mathrm{V}_{16}$ Influence of parents & & & & & & 0.77 \\
\hline $\mathrm{V}_{17}$ The university uses the same bank & & & & & & 0.77 \\
\hline
\end{tabular}


Table 8. Rotated component matrix showing the loading of the variables on the factors for the female sample.

\begin{tabular}{|c|c|c|c|c|}
\hline \multirow{2}{*}{ Variable } & \multicolumn{4}{|c|}{ Components (factors) } \\
\hline & 1 & 2 & 3 & 4 \\
\hline$V_{1}$ Professionalism of bank staff & 0.78 & & & \\
\hline $\mathrm{V}_{2}$ Pleasant bank atmosphere & 0.72 & & & \\
\hline $\mathrm{V}_{3}$ Reputation of the bank & 0.72 & & & \\
\hline $\mathrm{V}_{4}$ Staff courtesy & 0.71 & & & \\
\hline $\mathrm{V}_{5}$ Appropriate range of service offered & 0.64 & & & \\
\hline $\mathrm{V}_{6}$ The university uses the same bank & & 0.76 & & \\
\hline $\mathrm{V}_{7}$ Financial benefits & & 0.69 & & \\
\hline $\mathrm{V}_{8}$ Service provision (range of products on offer) & & 0.65 & & \\
\hline$V_{9}$ Proximity to the university & & 0.65 & & \\
\hline $\mathrm{V}_{10}$ Integration of mobile money services & & & 0.81 & \\
\hline $\mathrm{V}_{11}$ Mobile banking facilities & & & 0.78 & \\
\hline $\mathrm{V}_{12}$ Convenience banking & & & 0.62 & \\
\hline $\mathrm{V}_{13}$ Availability of ATM on campus & & & & 0.81 \\
\hline $\mathrm{V}_{14}$ Availability of 24 hours ATM service & & & & 0.80 \\
\hline
\end{tabular}

of the loadings, so that those with higher loadings take precedence of over those with lower loadings in the arrangement of the variables for each factor.

Factor 1 of the male final factor solution has $V_{1}$-internet banking, $V_{2}$-digital platforms, $\mathrm{V}_{3}$-integration of mobile money services and $\mathrm{V}_{4}$ - security-loading on it. Looking at the loadings and the nature of these variables, Factor 1 was named "secure e-banking" as the variables associated with it suggest the use of digital technology to offer services that are insulated against digital banking fraud. The indicator variables $\mathrm{V}_{5}$-staff curtesy, $\mathrm{V}_{6}$ - professionalism of bank staff and $\mathrm{V}_{7}$-pleasant bank atmosphere, express Factor 2. These variables concern the way customers are treated or the impression they get when they interact with the bank. Factor 2 was therefore named "customer experience". Factor 3 was named "promotion strategy" as the variables loading on it, $\mathrm{V}_{8}$-promotion strategy and $\mathrm{V}_{9}$-service provision (range of products on offer) and $\mathrm{V}_{10}$-convenience banking, have to do with creating products and services that come at the convenience of customers in order to entice and retain their custom. The variables $\mathrm{V}_{11}$-convenient branch location, $\mathrm{V}_{12}$-appropriate range of service offered and $\mathrm{V}_{13}$ - provision of fast and efficient service, concern cleverly proffering customers products and services that meet their expectations. While what these indicator variables together express (Factor 4) is similar to Factor 3, it differs from Factor 3 in the clever way the needs of customers are responded to. Factor 4 was thus named "intelligent responsiveness". The two variables loading on Factor 5, $\mathrm{V}_{14}$-availability of 24 hours ATM service and $\mathrm{V}_{15}$-availability of 
ATM on campus, have to do with the handiness of ATMs in terms of proximity and time. Factor 5 was therefore named "access to ATMs". Factor 6 was named "third party influence" because $\mathrm{V}_{16}$-influence of parents and $\mathrm{V}_{17}$ - the university uses the same bank, which load on the factor, describe the effect of third parties on the decision of students in selecting one bank over the other.

We now turn our attention on the final factor solution of the female sample (Table 8). Factor 1 is named "customer experience" as the first two of the variables ( $\mathrm{V}_{1}$ - professionalism of bank staff, $\mathrm{V}_{2}$ - pleasant bank atmosphere), which are more consistent with the proposed name for the factor, load highly on it than the other three variables $\left(\mathrm{V}_{3}\right.$-reputation of the bank, $\mathrm{V}_{4}$ - staff courtesy, $\mathrm{V}_{5}$ appropriate range of service offered) loading on the factor. It is also worthy of note that $\mathrm{V}_{3}, \mathrm{~V}_{4}$ and $\mathrm{V}_{5}$ are in some sense related to the highest loading variable $\mathrm{V}_{1}$, in particular $\mathrm{V}_{4}$. Factor 3 and Factor 4 are, mutatis mutandis, named "e-banking" and "access to ATMs" for similar reason as those adduced for analogous factors identified for the male factor solution. It was not easy to name Factor 2 as it is loaded on by an eclectic mix of variables. However, going by the fact that the highest loading variable on a factor is the most influential, Factor 2 was named "third party influence". Thus for the male and female samples, the factors that are thought to influence bank choice are as shown in Table 9.

The results show that while both males and females place importance on e-banking, it is more important to the males than the females as it has more prominence (the first factor) in the male sample than in the female sample (the third factor), and (as the names of the factors exemplify: "secure e-banking" for males and "e-banking" for females) the males tend to be more concerned with the security aspect of the facility than the females. "Customer experience" ranks second in the male sample but first in the female sample. This is not surprising as evidence from the literature appears to lend credence to the view that females tend to be more attracted to the "softer side" of their dealings with banks than males; Cicic, Brkic, and Agic [6] found that relaxed and friendly environment at banks mattered more to females than males. "Third party influence" also presents another instance where a factor rates higher on the female side than on the male

Table 9. Factors that influence bank choice by male and female students, presented in order diminishing influence.

\begin{tabular}{clcl}
\hline \multicolumn{2}{c}{ Male } & \multicolumn{1}{c}{ Female } \\
\hline No. & \multicolumn{1}{c}{ Factors } & No. & \multicolumn{1}{c}{ Factors } \\
\hline 1 & Secure E-banking & 1 & Customer Experience \\
2 & Customer Experience & 2 & Third Party Influence \\
3 & Promotion Strategy & 3 & E-banking \\
4 & Intelligent Responsiveness & 4 & Access to ATMs \\
5 & Access to ATMs & & \\
6 & Third Party Influence & & \\
\hline
\end{tabular}


side. It is the second ranking factor for the female sample and sixth for the male sample. Again, this is consistent with the finding of Cicic, Brkic, and Agic [6] that females attach importance to recommendations by family and friends. There is yet another instance where females place premium on a factor more than do their male counterparts. "Access to ATMs" is fourth on the female side and fifth on the male side. This is in line with what Mokhlis et al. [7] found, that females see availability of Automated Teller Machines (ATMs) as key in making bank choice.

As can be seen in Table 9, the males have two more factors than the females: namely, "promotion strategy" and "intelligent responsiveness" which are placed third and fourth in terms of prominence, higher than "access to ATMs" and "third party influence". The range of factors adduced for the males and their relative importance, appear to suggest the males are relatively more broad-based and tactical in terms of what motivates bank choice than the females, having in mind "promotion strategy" and "intelligent responsiveness" in particular. Indeed, this is buttressed by Mokhlis [4], who observed that males tended to be more attracted to marketing promotions and financial benefits compared with females.

The results confirms the view that sex plays a significant role in determining consumer behavior and has an effect on banking preferences [1] [2]; male and female students of TTU appear to differ in what motivate their choice of banks in some respects.

\section{Conclusion}

A major objective of the study reported herein was to establish whether or not what motivates bank choice amongst male TTU students differed from that of the females. The foregoing results and discussions support the view that male Takoradi Technical University students differ from their female counterparts with respect to the factors that determine bank choice. While the females attached importance to relationships and the "softer side" of banking when selecting banks the males tended to be more strategic and more broad-based in their approach to selecting banks. The findings from the study indicate that there is the possibility of differences in banking preferences between male and female students in the broader technical university community. Finally, there is the need for further investigation into these bank selection preferences, focusing on the entire population of technical university students and possibly exploring further these differences among the wider population of Ghanaians, beyond the students segment. Banks, can then consider the differences in male and female preferences and design products and services along these preferences for them.

\section{Conflicts of Interest}

The authors declare no conflicts of interest regarding the publication of this paper. 


\section{References}

[1] Mitchell, V.W. and Walsh, G. (2004) Gender Differences in German Consumer Decision-Making Styles. Journal of Consumer Behaviour. An International Research Review, 3, 331-346. https://doi.org/10.1002/cb.146

[2] Kraft, H. and Weber, J.M. (2012) A Look at Gender Differences and Marketing Implications. International Journal of Business and Social Science, 3, 247-253.

[3] Heermann, T. (2010) 4 Gender Differences in Marketing Approach. https://www.marketitwrite.com/4-gender-differences-in-marketing-approach/

[4] Mokhlis, S. (2009) Determinants of Choice Criteria in Malaysia's Retail Banking: An Analysis of Gender-Based Choice Decisions. European Journal of Economics, Finance and Administrative Sciences, 1, 1450-1467.

[5] Srivatsa, H.S. and Srinivasan, R. (2008) New Age Youth Banking Behavior an Explorative Study in the Indian Banking Sector. Journal of Services Research, 8, 53.

[6] Čičić, M., Brkić, N. and Agić, E. (2004) Bank Selection Criteria Employed by Students in an Southeastern European Country: An Empirical Analysis of Potential Market Segments' Preferences. Australia and New Zealand Marketing Academic Conference, Wellington, 29 November - 1 December 2004, 56.

[7] Mokhlis, S., Mat, N.H.N. and Salleh, H.S. (2008) Commercial Bank Selection: Comparison between Single and Multiple Bank Users in Malaysia. International Journal of Economics and Finance, 1, 263-273. https://doi.org/10.5539/ijef.v1n2p263

[8] Amewu, G. and Mensah, S. (2014) Factors that Influence the Choice of Banks in Ghana. Review of Business Research, 14, 151-163.

https://doi.org/10.18374/RBR-14-3.14

[9] Baah, E.M., Amponsah, E.A. and Otoo, R.A. (2021) Determinants of Technical University Students' Choice of Banks: Empirical Evidence from Takoradi Technical University, Ghana. Open Journal of Statistics, 11, 351-368. https://doi.org/10.4236/ojs.2021.113021

[10] R Core Team (2020) R: A Language and Environment for Statistical Computing. R Foundation for Statistical Computing, Vienna, Austria. http://www.R-project.org/

[11] Hair, J.F., Black, W.C., Babin, B.J., Anderson, R.E. and Tatham, R. (2014) Multivariate Data Analysis. New International Edition, Pearson Education Ltd., London.

[12] Freund, J.E. (2001) Mathematical Statistics. 5th Edition. Prentice-Hall of India, New Delhi, India.

[13] Nsonwah-Nuamah, N.N.N. (2005) Basic Statistics. ACADEC Press, Accra.

[14] Johnson, R.A. and Wichern, D.W. (2007) Applied Multivariate Statistical Analysis. 6th Edition, Prentice-Hall, Upper Saddle River.

[15] Everitt, B.S. and Dunn, G. (2001) Applied Multivariate Data Analysis. Arnold/Hodder Headline Group, London. https://doi.org/10.1002/9781118887486

[16] Sharma, S. (1996) Applied Multivariate Techniques. John Wiley and Sons, Inc., Hoboken.

[17] Owusu-Frimpong, N. (1999) Patronage Behaviour of Ghanaian Bank Customers. International Journal of Bank Marketing, 17, 335-342. https://doi.org/10.1108/02652329910305698

[18] Azumah, S.B., Rahman, N.A. and Adzawla, W. (2014) The Determinants of Customers' Choice of Bank in the Tamale Metropolis of Ghana. ADRRI Journal (Multidisciplinary), 13, 16-31.

[19] Schmitt, T. (2016) Determining the Number of Factors with Parallel Analysis in R. 
https://www.r-bloggers.com/2016/04/determining-the-number-of-factors-with-para $\underline{\text { llel-analysis-in-r/ }}$

[20] Dinno, A. (2014) Gently Clarifying the Application of Horn's Parallel Analysis to Principal Component Analysis Versus Factor Analysis.

https://alexisdinno.com/Software/files/PA_for_PCA_vs_FA.pdf https://pdxscholar.library.pdx.edu/cgi/viewcontent.cgi?article $=1026 \&$ context $=$ com mhealth_fac 